\title{
Inconsistent VAP definitions raise questions of usefulness
}

Meg Harward

Clinical Nurse, Quality Team, Intensive Care Unit, Princess Alexandra Hospital, Ipswich Road, Woolloongabba QLD 4102, Australia

Alison Smith

Clinical Nurse, Quality Team, Intensive Care Unit, Princess Alexandra Hospital, Ipswich Road, Woolloongabba QLD 4102, Australia

Leanne M Aitken

Visiting Scholar, Princess Alexandra Hospital, Ipswich Road, Woolloongabba QLD 4102, Australia Professor of Critical Care Nursing, Menzies Health Institute Queensland, Griffith University, Nathan QLD 4111, Australia Professor of Nursing, School of Health Sciences, City, University of London, London EC1V 0HB United Kingdom

Please address all correspondence to:

Ms Meg Harward

Email; mharward@georgeinstitute.org.au

Ph.: 0405470919

and

Ms Alison Smith

Email: Alison.Smith4@health.qld.gov.au 
Ventilator associated pneumonia (VAP) is recognised as one of the most frequent nosocomial infection in Intensive Care Unit (ICU), with infection rates varying from $10-30 \%$ of mechanically ventilated patients. ${ }^{1-3}$ VAP is undoubtedly a burden on the health care system and has been associated with adverse patient outcomes; increases in ICU Length of stay (LOS), hospital LOS and crudely associated with increased mortality. ${ }^{1,4}$ Furthermore, it has been widely reported to impact on health care resources resulting in significant inflation of health care costs. ${ }^{5-7}$

VAP is broadly defined as pneumonia in persons who have had an invasive device, an endotracheal tube or tracheostomy, to assist ventilation continuously for at least 48hrs. Although, the devil is in the detail when applying the definition for quality surveillance purposes and its lack of objectivity and variability in interpretation is proving problematic for the critical care community. At present, there is little consensus on an effective surveillance definition for Ventilator Associated Pneumonia (VAP). Varying definitions and terminology have existed over time, notably The Centres for Disease Control and Prevention (CDC) provide the most widely-used and reported definition for VAP surveillance. The complexity of the previous definition, ${ }^{3}$ and lack of objectivity and sensitivity has posed doubt over its reliability as a benchmarking tool. ${ }^{8}$

The CDC addressed these limitations in September 2011 by establishing a VAP Surveillance Working Group, consisting of clinical experts and stakeholders in the field. ${ }^{9}$ Accordingly a revised three tiered definition to be used for surveillance of Ventilator Associated Events (VAE) was introduced by the CDC in January $2013 .{ }^{10}$ In light of the changing definition, the PAH (Princess Alexandra Hospital) ICU Quality Taskforce recognised the potential impact of the change in definitions on benchmarking activities and undertook a unit based comparison of the 2009 and 2013 definitions. We hypothesised little concordance between patients classified as VAP (PNU1-Clinically defined pneumonia, PNU2-Pneumonia with specific laboratory findings, PNU3-Pneumonia in immunocompromised patients) according to the 2009 definition compared to patients diagnosed with VAE (Ventilator Associated Event) (VAC-Ventilator Associated Condition, IVAC-Infection-Related VentilatorAssociated Complication, Possible VAP or Probable VAP) on the 2013 criteria (Table 1). 
Table 1: Comparison of 2009 and 2013 VAP/VAE definitions

\begin{tabular}{|c|c|}
\hline $\begin{array}{l}\text { CDC } 2009 \text { Definition: Ventilator Associated } \\
\text { Pneumonia (VAP) }\end{array}$ & $\begin{array}{l}\text { CDC } 2013 \text { Definition: Ventilator Associated Event } \\
\text { (VAE) }\end{array}$ \\
\hline $\begin{array}{l}\text { - All mechanically ventilated patients with positive } \\
\text { Chest X-Ray reports (new or progressive and } \\
\text { persistent infiltrates, consolidation or cavitation) } \\
\text { Temp }>38^{\circ} \text { and/or WCC }<4.0 \times 10^{9} / \mathrm{L} \text { or }>12.0 \mathrm{x} \\
10^{9} / \mathrm{L} \\
\text { - At least two respiratory symptoms of tachypnoea } \\
\text { or dyspnoea, rales or bronchial breath sounds, } \\
\text { worsening gas exchange ( } \mathrm{PaO} 2 / \mathrm{FiO} 2 \leq 240 \text { ), } \\
\text { evidence of new onset of purulent sputum } \\
\text { (leukocytes } 2+\text { ) and/or cough, and/or pleuritic } \\
\text { chest pain or haemoptysis (in } \\
\text { immunocompromised patients) or }>70 \text { years with } \\
\text { an altered mental status. } \\
\text { NB. Patients were excluded if they were admitted with } \\
\text { a respiratory infection, or if there was a likelihood of } \\
\text { aspiration pre intubation by a modified rule (a GCS }<8 \\
\text { documented pre intubation). }\end{array}$ & 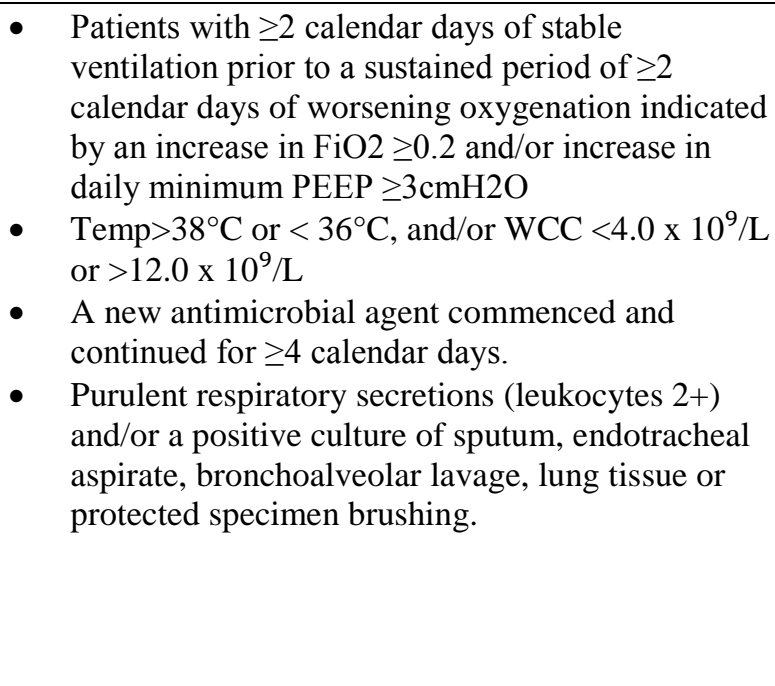 \\
\hline
\end{tabular}

All mechanically ventilated patients admitted to the PAH General ICU over a three month period, April to June 2013 ( $n=253)$, were assessed by one of three ICU trained Quality Clinical Nurses for each of the criteria for the diagnosis of PNU 1, 2 or 3 (2009 VAP) or VAC, IVAC, Possible / Probable VAP (2013 VAE); this assessment was then reviewed by at least one of three Consultant Intensivists who were designated members of the ICU Quality Taskforce. Ethical approval was received from Metro South Human Research Ethics Committee.

Patients were 53.1 (SD 19.3) years old; two thirds (67\%) male; had a median (IQR) APACHE II of 18 (12-22) and stayed in ICU median (IQR) 3 (1-7) days. ICU mortality was 10.3\%, while hospital mortality was $14.6 \%$. Two patients satisfied the 2009 criteria (VAP rate 1.8/1000 ventilator days) while six different patients from the same cohort satisfied the 2013 criteria (VAE rate 5.6/1000 ventilator days) (Table 2). 
Table 2: Characteristics of patients diagnosed with VAP/VAE

\begin{tabular}{|c|c|c|c|c|c|c|c|c|c|}
\hline \multicolumn{5}{|c|}{ VAP $1.8 / 1000$ ventilator days } & \multicolumn{5}{|c|}{$\begin{array}{l}\text { VAE } 5.6 / 1000 \text { ventilator days } \\
\end{array}$} \\
\hline $\begin{array}{l}\text { VAP } \\
\text { Classification }\end{array}$ & AGE & Day & LOS & $\begin{array}{l}\text { Admission } \\
\text { Diagnosis }\end{array}$ & $\begin{array}{l}\text { VAE } \\
\text { Classification }\end{array}$ & AGE & Day & LOS & $\begin{array}{l}\text { Admission } \\
\text { Diagnosis }\end{array}$ \\
\hline PNU1 & 34 & 11 & 38 & $\begin{array}{l}\text { Spinal/Multi } \\
\text { trauma }\end{array}$ & VAC & 51 & 9 & 17 & $\begin{array}{l}\text { Neurological } \\
\text { Encephalitis }\end{array}$ \\
\hline PNU2 & 26 & 5 & 14 & $\begin{array}{l}\text { Neurological } \\
\text { Haemorrhage/ } \\
\text { intracranial } \\
\text { haematoma }\end{array}$ & VAC & 34 & 5 & 12 & $\begin{array}{l}\text { Trauma } \\
\text { Chest/extremity }\end{array}$ \\
\hline & & & & & IVAC & 62 & 27 & 81 & $\begin{array}{l}\text { Coronary artery } \\
\text { bypass grafting }\end{array}$ \\
\hline & & & & & IVAC & 32 & 3 & 28 & $\begin{array}{l}\text { Trauma Isolated } \\
\text { cervical spine } \\
\text { injury }\end{array}$ \\
\hline & & & & & & 46 & 7 & 25 & $\begin{array}{l}\text { Gastrointestinal } \\
\text { GI Abscess/cyst }\end{array}$ \\
\hline & & & & & Probable VAP & 19 & 5 & 14 & $\begin{array}{l}\text { Trauma Isolated } \\
\text { cervical spine }\end{array}$ \\
\hline
\end{tabular}

Day: Day of ICU admission when VAP/VAE diagnosis made

In this cohort of mechanically ventilated patients from a tertiary hospital there was no concordance between VAP and VAE data representing the first known report of this discrepancy in the Australian setting; this finding is consistent with international reports ${ }^{11,12}$ and suggests that VAP and VAE surveillance data are not interchangeable. The problem of inconsistency in diagnosis or surveillance rates has also been demonstrated across a range of six different sets of diagnostic criteria, ${ }^{13}$ with the incidence of VAP ranging from $4-42 \%$. These findings also support the notion that surveillance rates can be manipulated depending on which criteria you use and initiatives designed to increase the rigour of surveillance can have the effect of biasing VAP rates. ${ }^{14}$ Use of both these definitions for quality surveillance has proven to be labour intensive, and given the ambiguity in both diagnosis and relationship to outcome, scrutiny of whether this is the best use of resources is essential.

A lack of consistency in surveillance rates dependent on which definitions are used means that comparison over time, or between institutions on a national or international scale, is not possible unless everyone agrees to use the same criteria. Further, use of these data in public reporting or to fund or penalise healthcare organisations is not possible until there has been development and agreement of criteria that are less subjective and examination of the subsequent impact of outcomes. ${ }^{15,16}$ 


\section{Acknowledgements:}

Thanks to Drs Peter Kruger, James Walsham and Anand Krishnan for their contribution to the screening of patients for this project.

\section{References}

1. Labeau SO, Van de Vyver K, Brusselaers N, Vogelaers D, Blot SI. Prevention of ventilatorassociated pneumonia with oral antiseptics: a systematic review and meta-analysis. Lancet Infect Dis 2011;11(11):845-54.

2. Chitnis AS, Edwards JR, Ricks PM, Sievert DM, Fridkin SK, Gould CV. Device-associated infection rates, device utilization, and antimicrobial resistance in long-term acute care hospitals reporting to the National Healthcare Safety Network, 2010. Infect Control Hosp Epidemiol 2012;33(10):993-1000.

3. Centers for Disease Control and Prevention (CDC). Ventilator-Associated Pneumonia (VAP) Event: Centers for Disease Control and Prevention; 2014 [10/10/2016]. Available from: http://www.cdc.gov/nhsn/PDFs/pscManual/6pscVAPcurrent.pdf (accessed 10/10/2016).

4. Miller MA, Arndt JL, Konkle MA, Chenoweth CE, Iwashyna TJ, Flaherty KR, et al. A polyurethane cuffed endotracheal tube is associated with decreased rates of ventilator-associated pneumonia. J Crit Care 2011;26(3):280-6.

5. Thomas BW, Maxwell RA, Dart BW, Hartmann EH, Bates DL, Mejia VA, et al. Errors in administrative-reported ventilator-associated pneumonia rates: are never events really so? Am Surg 2011;77(8):998-1002.

6. Muscedere JG, Martin CM, Heyland DK. The impact of ventilator-associated pneumonia on the Canadian health care system. J Crit Care 2008;23(1):5-10.

7. Nair GB, Niederman MS. Nosocomial pneumonia: lessons learned. Crit Care Clin 2013;29(3):521-46.

8. Klompas M. Ventilator-associated conditions versus ventilator-associated pneumonia: different by design. Current infectious disease reports 2014;16(10):430.

9. Magill SS, Klompas M, Balk R, Burns SM, Deutschman CS, Diekema D, et al. Developing a new, national approach to surveillance for ventilator-associated events*. Crit Care Med 2013;41(11):2467-75.

10. Centers for Disease Control and Prevention (CDC). Ventilator-Associated Event (VAE): Centers for Disease Control and Prevention 2014 [10/10/2016]. Available from: http://www.cdc.gov/nhsn/pdfs/pscmanual/10-VAE FINAL.pdf (accessed 10/10/2016).

11. Kallet RH. The Vexing Problem of Ventilator-Associated Pneumonia: Observations on Pathophysiology, Public Policy, and Clinical Science. Respir Care 2015;60(10):1495-508.

12. Chastre J, Luyt CE. Does this patient have VAP? Intensive Care Med 2016;42(7):1159-63.

13. Ego A, Preiser JC, Vincent JL. Impact of diagnostic criteria on the incidence of ventilatorassociated pneumonia. Chest 2015;147(2):347-55.

14. Klompas M. Is a ventilator-associated pneumonia rate of zero really possible? Current opinion in infectious diseases 2012;25(2):176-82.

15. Himmelstein DU, Ariely D, Woolhandler S. Pay-for-performance: toxic to quality? Insights from behavioral economics. Int J Health Serv 2014;44(2):203-14.

16. Duckett S, Daniels S, Kamp M, Stockwell A, Walker G, Ward M. Pay for performance in Australia: Queensland's new Clinical Practice Improvement Payment. J Health Serv Res Policy 2008;13(3):174-7. 